\title{
Protagonismo juvenil: cooptação ou emancipação dos jovens?
}

\begin{abstract}
Resumo:
O presente artigo tem como objetivo problematizar o conceito de "protagonismo juvenil" e propor sua ressignificação de maneira a afastá-lo do sentido neoliberal e endosso dessa ordem socioeconômica, tornando-o uma forma de emancipação dos jovens. Discussão bibliográfica - Souza (2006) e Ferretti et al. (2004) - e de documentos curriculares da educação - Currículo da Cidade de São Paulo (2017) e Base Nacional Comum Curricular (2018) -, e apresentação de resultados de estudo de caso constituem a metodologia utilizada. Traçando um histórico dos sentidos do protagonismo e sua circulação por documentos nacionais e internacionais e organizações da sociedade civil, nestas últimas a partir dos trabalhos do pedagogo Antônio Carlos Gomes da Costa, apontamos sua acolhida pela escola e o sentido que adquire na prática de uma escola municipal de ensino fundamental localizada em São Paulo que, apesar de não conceituar o termo em seu Projeto Político Pedagógico, deixando espaço para múltiplas interpretações, se contrapõe à cooptação.
\end{abstract}

\section{Palavras-chave:}

Protagonismo juvenil. Participação. Escola. Educação. Práticas pedagógicas.

\section{Youth protagonism: cooptation or emancipation of young people?}

\begin{abstract}
This article aims to discuss the concept of "youth participation" and propose their reinterpretation in order to remove it from neoliberal direction and endorsement of this socioeconomic order, making it a form of emancipation of young people. Bibliographic discussion - Souza (2017) e Ferretti et al. (2004) - and education curricular documents - educação - Currículo da Cidade de São Paulo (2017) e Base Nacional Comum Curricular (2018) -, and presentation of case study results constitute the methodology used. Tracing a history of the meanings of protagonism and its circulation by national and international documents and civil society organizations, in these last ones from the works of pedagogue Antônio Carlos Gomes da Costa, we point out its acceptance by the school and the meaning it acquires in the practice of a public elementary school located in São Paulo, which, despite not conceptualizing the term in its Political Pedagogical Project, leaving space for multiple interpretations, is opposed to cooptation.
\end{abstract}

Keywords: Youth protagonism. Participation. School. Education. Pedagogical practices.

1 Mestra em Educação, Professora da Rede Municipal de Ensino de São Paulo. E-mail: thasiqueira@yahoo.com.br. ORCID iD: http://orcid.org/0000-0002-3961-7775. 


\section{Protagonismo juvenil: ¿cooptación o emancipación de los jóvenes?}

Resumen: Este artículo pretende problematizar el concepto de "protagonismo juvenil" y proponer su resignificación de manera que lo aleje del sentido neoliberal y del aval de este orden socioeconómico, convirtiéndolo en una forma de emancipación de los jóvenes. Discusión bibliográfica - Souza (2017) y Ferretti et al. (2004) -y documentos curriculares educativos - Currículo da Cidade de São Paulo (2017) y Base Nacional Comum Curricular (2018) -, y la presentación de los resultados de los estudios de caso constituyen la metodología utilizada. Trazando una historia de los significados del protagonismo y su circulación por documentos nacionales e internacionales y organizaciones de la sociedad civil, en estos últimos de la obra del pedagogo Antônio Carlos Gomes da Costa, señalamos su aceptación por parte de la escuela y el significado que adquiere en la práctica de una escuela municipal ubicada en São Paulo, que, a pesar de no conceptualizar el término en su Proyecto Político Pedagógico, dejando espacio para múltiples interpretaciones, se opone a la cooptación.

Palabras clave: Protagonismo juvenil. Participación. Escuela. Educación. Prácticas pedagógicas.

\section{O protagonismo juvenil em retrospecto}

Os estudos em torno do "protagonismo juvenil” ganharam impulso no início dos anos 2000. Pesquisa realizada no Catálogo de Teses e Dissertações da Capes em 2019 localizou 218 pesquisas realizadas entre 2000 e 2018 .O termo, no entanto, já surgia em documentos de organismos internacionais, organizações não-governamentais (ONGs), órgãos de governo e no discurso de educadores desde meados da década de 1990, sempre como referência a uma determinada forma de participação da juventude na sociedade. Aparece com destaque, por exemplo, nas Diretrizes Curriculares Nacionais para o Ensino Médio (DCNEM)', em 1998 (CNE, 1998).

Inicialmente, trouxe o protagonismo para a minha dissertação de mestrado (SIQUEIRA, 2020) de forma ingênua, sem me atentar para como estava sendo significado. Ao tomar contato com pesquisas sobre o tema, porém, percebi como o conceito tem sido apropriado pelo neoliberalismo, sendo usado para cooptar e inserir a juventude, principalmente a juventude pobre, nesta ordem socioeconômica. Como explicam Ferreti et al., pesquisadores da Fundação Carlos Chagas, em artigo escrito em 2004:

Caberá aos professores, pesquisadores e especialistas o trabalho constante de desbastar os sutis vieses ideológicos desse 'inferno semântico’ de que nos fala Veríssimo (apud FRIGOTTO; CIAVATTA, 2002), de modo que a necessária promoção do protagonismo juvenil se afaste de um mero ativismo social - acrítico e apenas psicologicamente compensatório - ou da simples adaptação dos jovens às perversas condições da atual ordem socioeconômica. (FERRETI et al., 2004, p. 422).

Com base na contraposição de referenciais bibliográficos e do estudo de caso realizado em uma escola municipal da cidade de São Paulo, revisito os sentidos do termo protagonismo juvenil numa perspectiva temporal em suas diferentes formulações e busco ressignificá-lo de modo a fugir do endosso à ordem neoliberal, transformando-o em uma proposta de participação e emancipação real dos estudantes. Adotei como referencial crítico a tese de Regina Magalhães de Souza (2006), $O$ discurso do protagonismo juvenil, o artigo de Ferretti et al. (2004), Protagonismo Juvenil na literatura especializada e na reforma do Ensino Médio, a dissertação de Bianca Klein (2004), Protagonismo Juvenil e Cidadania: uma proposta pedagógica burguesa, e documentos referenciais de educação².

1 Estabelecidas pelo Conselho Nacional de Educação pela Resolução CEB/CNE n. 03/98 (CNE, 1998a), que integra o Parecer n. 15/98 da Câmara de Educação Básica do Conselho (CNE, 1998b).

2 As referências completas podem ser encontradas ao final deste artigo. 
A pesquisa de Souza (2006) historiciza, localiza e delimita os sentidos aglutinados na expressão "protagonismo juvenil", ponto de convergência entre os discursos: do empresariado e da iniciativa individual; do terceiro setor e, no seu interior, do voluntariado e da solidariedade; e da valorização da educação como solução dos problemas nacionais (SOUZA, 2006, p. 16). Em nome do protagonismo juvenil,

jovens e ONGs espalhados por todo o Brasil têm prestado serviços gratuitos à coletividade, prática nomeada, geralmente, de trabalho voluntário e explicada por meio da valorização da cidadania, da educação, da solidariedade. Veiculam a ideia de que iniciativas particulares podem ser bem-sucedidas na 'solução dos problemas sociais', e tentam desmentir a imagem da juventude apática e alienada, predominante na sociedade desde o arrefecimento do movimento estudantil. (SOUZA, 2006, p. 8).

A socióloga mostra que a palavra "protagonista" designava, originalmente, o principal competidor dos jogos públicos, mas também de uma assembleia, reunião, luta judiciária ou processo. Logo, a ideia de luta e de um espaço público - onde se travam as lutas corporais ou verbais - encontram-se na formação inicial do vocábulo. No entanto, recorrer à origem etimológica do protagonismo pode concorrer, ainda de acordo com Souza (2006), para uma peculiar operação discursiva: uma assepsia da palavra, em que permanece a ideia de espaço público - e, portanto, de política -, porém de um espaço público transformado em cenário, em que não existe luta e em que os lutadores são substituídos pelos atores sociais. Desta metáfora teatral surge o "jovem protagonista", ou seja, o "ator principal" que tem uma "atuação prática" na "solução" dos problemas sociais.

Assim, o jovem protagonista é invariavelmente lembrado como o 'ator principal' no cenário público, posição de destaque que supõe algum tipo de ação política. Contudo, uma ação política despida da luta e transformada em atuação social [...]. O apelo ao protagonismo ou à posição principal presta-se, sobretudo, para motivar os jovens à integração. (SOUZA, 2006, p. 8-9).

Nos anos 2000, o temor da desestabilização social provocada pela situação de pobreza e exclusão de grandes parcelas da população juvenil, servia como base de grande parte das explicações para sua adesão às drogas e à violência ${ }^{3}$. Sendo assim, a participação da juventude tornou-se um meio de evitar o descontrole e assegurar a coesão social, sustentada mais pela motivação do jovem do que por mecanismos de coerção, disciplinamento ou repressão. Tal situação deslocou as interpretações dos estudos sobre juventude da noção de crise para a situação de exclusão-inclusão, enfatizando a preocupação dos governos e organismos internacionais com a integração da juventude pobre, que vive uma situação considerada como de exclusão ${ }^{4}$. A ideia de "ameaça juvenil" também se deslocou. Logo, a imagem do "jovem como problema" dá lugar a do "jovem como solução". Souza afirma, então, que o protagonismo juvenil é um discurso que suscita no jovem a necessária motivação para ser integrado,

na medida em que manifesta uma suposta posição de destaque da juventude diante do objetivo de uma certa mudança social e apela ao 'sentir-se útil' ou à valorização do indivíduo que se propõe a fazer coisas, base das 'novas formas' de política. (SOUZA, 2006, p. 9).

\footnotetext{
3 Souza cita um documento da UNESCO de 2005 que diz que "o estímulo à 'participação cidadã juvenil' é considerado uma das estratégias de prevenção da violência” (UNESCO, 2005 apud SOUZA, 2006, p. 72).

4 Na primeira seção do capítulo “Em busca de 'novas formas' de política”, Regina Magalhães de Souza (2006) dedica-se a trazer as discussões em torno dos conceitos de "juventude" e "adolescência", sendo que este último foi abordado no primeiro capítulo desta dissertação. As ideias de "transição", "crise" e "moratória", bem como a construção histórica deste momento da vida aparecem neste ponto. Souza estabelece a diferença entre "crise da juventude" e "crise da adolescência", aquela relativa à experiência grupal e esta a uma experiência individual do sujeito.
} 
Nesta "nova forma" de política, a mudança social seria resultado da atividade direta do indivíduo, fincada no "fazer". Não é modalidade de rebelião juvenil, mas constitui mecanismo de integração da juventude e as instâncias na qual ocorre não são os partidos, sindicatos ou movimentos sociais, ideologicamente enfraquecidos e desacreditados, mas predominantemente as organizações do terceiro setor (SOUZA, 2006, p. 14).

Souza prossegue, apontando que o protagonismo juvenil é um discurso de adultos, produzido e compartilhado pelos organismos internacionais, órgãos governamentais, ONGs, empresários e educadores, ou seja, pelos adultos que se dedicam à integração da juventude, considerada objeto de intervenção. A ação juvenil ligada à execução de projetos e medidas equivale ao fazer, atividade que acrescenta coisas ao mundo, mas não interfere na mudança de seu curso. Para Souza, embora evoque as ideias da distinção e do destaque, e funcione, certas vezes, como uma espécie de símbolo de "avanço" pedagógico, político ou social, o protagonismo juvenil é um simulacro, posto que o jovem do discurso não é sujeito, mas, sim, objeto de políticas e medidas governamentais e não-governamentais (SOUZA, 2006, p. 15-16). Conforme análise de Nonato et al. (2016, p. 280),

Em nome do protagonismo juvenil, o que vemos ocorrer é uma instrumentalização da ação dxs jovens e sua responsabilização por intervenções sociais complexas e descontextualizadas. É muito comum também não serem escutadxs ou levadxs em conta na definição dos temas e conteúdos a serem trabalhados.

No que tange ao discurso do protagonismo construído nos documentos de organismos internacionais - sobretudo da Comissão Econômica para a América Latina e Caribe (CEPAL) e da Organização das Nações Unidas para Educação, Ciência e Cultura (Unesco) - nada é imposto, mas sim compartilhado: a conciliação e o consenso são forjados, obstruindo a possibilidade de surgimento de posições contrárias que pudessem se manifestar por meio de contra-discursos (SOUZA, 2006, p. 68). Parece-nos difícil construir um contra-discurso visto que os temas centrais destes documentos são bastante caros a qualquer sociedade: o desenvolvimento, a educação, o potencial e a participação juvenis. Entretanto, os sentidos dados a estes temas carregam o ideário neoliberal.

No Brasil, Souza (2006) localiza como o primeiro uso do termo "protagonismo juvenil" um artigo publicado em 1996, em informativo da Fundação Odebrecht. Protagonismo juvenil: projetos estimulam adolescentes a atuarem como agentes de ações voltadas para a comunidade sintetizava, segundo a pesquisadora, alguns dos pontos principais do discurso já consolidado: a adoção dos projetos como estratégia pedagógica ${ }^{5}$ a noção de atuação (que supõe a noção de ator social) concomitante à noção de atividade (ou o fazer) como o modelo de participação na sociedade; uma má definida ideia de "comunidade", que tem a função de indicar que se trata de atividades locais, dirigidas a segmentos populacionais específicos e demarcados, e não a "sociedade", mais ampla, mais geral e, supõe-se, fora do alcance (SOUZA, 2006, p. 118). Nos documentos internacionais o termo aparece pela primeira vez na Declaração de Lisboa (Organização das Nações Unidas - ONU), divulgado em 1998. O discurso sobre o protagonismo juvenil, no entanto, já se encontrava manifesto nos documentos internacionais produzidos desde 1985, faltando apenas nomeá-lo.

Tanto Souza (2006) quanto Ferretti et al. (2004) apontam a imprecisão desse conceito. Estes últimos mostram que o "protagonismo dos jovens/alunos"

\footnotetext{
5 Souza aponta que o "enfoque de projetos" foi adotado pela pedagogia e tornou-se a linha mestra de trabalho adotada pelas ONGs que se lançaram no campo da educação não-formal, comparecendo também nas propostas curriculares dos ensinos superior e médio - neste último, o projeto estava previsto nos Parâmetros Curriculares Nacionais, como uma das metodologias alternativas ao "ensino tradicional". As ONGs se responsabilizam diretamente pela sua execução ou, indiretamente, por meio da destinação de recursos financeiros e técnicos a outras organizações, formando, assim, uma "parceria". Mesmo aquelas que não explicitam o protagonismo juvenil adotaram o projeto como estratégia de trabalho com jovens. De maneira geral, o projeto reúne pelo menos dois quesitos fundamentais da concepção atual de educação: é uma atividade prática, dispensando "teorias" e "conteúdos inúteis", e é uma atividade de grupo, oportunidade de "aprendizagem" da sociabilidade (SOUZA, 2006, p. 203-206).
} 
[...] é um conceito passível de diferentes interpretações e, além disso, imbrica outros conceitos igualmente híbridos, como 'participação', 'responsabilidade social', 'identidade', 'autonomia' e 'cidadania'. Nem mesmo a distinção conceitual entre 'participação' e 'protagonismo' é clara na bibliografia consultada.

Ou seja, um autor pode-se referir a 'protagonismo' em contextos em que outro falaria de 'participação', e vice-versa, havendo, ainda, casos em que as duas expressões são usadas como sinônimos (FERRETTI et al., 2004, p. 413).

Conforme apontado anteriormente, o enunciado "protagonismo juvenil" encontra em organizações da sociedade civil como a Fundação Educar DPaschoal (criada em 1989), o Instituto Ayrton Senna (criado em 1994) e a Fundação Odebrecht (fundada em 1965, dirigindo suas atividades aos adolescentes a partir de 1988), um lugar para sua divulgação e consolidação (SOUZA, 2006, p. 117). Esta última, inclusive, além de ter veiculado artigo sobre o assunto, publicou no ano de $2000 \mathrm{o}$ livro Protagonismo juvenil: adolescência, educação e participação democrática, escrito pelo pedagogo Antônio Carlos Gomes da Costa, apresentando o trabalho com adolescentes desenvolvido pela instituição. A partir desta publicação, "protagonismo juvenil" passou a identificar um conjunto de práticas e noções que já compunham, desde o início da década de 1990, um certo modelo de participação da juventude na sociedade (SOUZA, 2006, p. 122-124).

Costa tornou-se referência entre as organizações governamentais e não-governamentais que elegeram a juventude como protagonista. Iniciou sua trajetória profissional como professor de supletivo e dos ensinos fundamental e médio. Em seguida, dirigiu, por quase sete anos, a Escola Barão de Camargos, da antiga Febem (Fundação Estadual para o Bem Estar do Menor), em Ouro Preto, e chegou a presidir a instituição durante o governo Tancredo Neves (1983-1984) em Minas Gerais. Desde então, exerceu diversas atividades: Secretário de Educação de Belo Horizonte, oficial de projetos do Fundo das Nações Unidas para a Infância (Unicef) e consultor da Organização Internacional do Trabalho (OIT) e da Unesco, além de vários órgãos federais, estaduais e municipais em todo o país.

O pedagogo também foi membro do Comitê Internacional dos Direitos da Criança da ONU, na Suíça, e colaborou na criação da Convenção Internacional sobre os Direitos da Criança e do Estatuto da Criança e do Adolescente (ECA). Quando faleceu, em 2011, era integrante de conselhos de diversas fundações e exercia o cargo de diretor da Modus Faciendi, empresa de consultoria em responsabilidade social e educação que havia criado em 1991 e muito provavelmente teve suas atividades encerradas após a sua morte, uma vez que não encontrei mais nenhuma informação sobre ela nas pesquisas realizadas.

Enquanto o site da consultoria de Costa esteve no ar, Souza coletou ${ }^{7}$ uma lista de 22 cursos que eram oferecidos, sendo exemplos "Adolescência, educação e trabalho no limiar do século XXI", "Protagonismo juvenil: a formação do jovem autônomo, solidário e competente", "Promovendo e desenvolvendo a resiliência", "Tempo de crescer: adolescência, cidadania e participação" e "Educação para valores".

Esses cursos evidenciam a preocupação com a integração e formação da juventude segundo preceitos da ordem neoliberal: a formação escolar se dá para o trabalho e aquisição de valores que interessam ao neoliberalismo, formulados no lema do "Relatório Delors" $(2003)^{8}$ - aprender a ser, aprender a

6 Costa ainda publicou outros textos sobre o tema - O adolescente como protagonista (1999) e Protagonismo juvenil: educação para a cidadania (1997/98) - e sua empresa, a Modus Faciendi, produziu o vídeo educativo Protagonismo Juvenil: a construção do jovem autônomo, solidário e competente [2000?].

7 De acordo com o texto que consta no Anexo J de sua tese, Souza (2006) parece ter recolhido as informações sobre a Modus Faciendi entre 2003 e 2006

8 Jacques Lucien Jean Delors, economista e político francês, presidiu a Comissão Internacional sobre Educação para o Século XXI, da UNESCO, de 1992 a 1996. Foi um dos autores do relatório “Educação, um Tesouro a descobrir", conhecido como "Relatório Delors", em que explora os "Quatro Pilares da Educação", mencionados no texto. Durante seu trabalho na UNESCO, apontou como principal consequência 
conviver, aprender a aprender e aprender a fazer; o protagonismo juvenil serve ao propósito de "treinar" o jovem para a autonomia', solidariedade (sinônimo de trabalho voluntário) e a competência; a resiliência para enfrentar a instabilidade do mercado de trabalho e as desigualdades sociais; e a cidadania que equivale à participação, ou seja, ao fazer esvaziado da política (SOUZA, 2006).

Bianca Klein (2004) destaca que, para Costa, a expressão "protagonismo juvenil” designa a participação de adolescentes atuando como parte da solução, no enfrentamento de situações reais na escola, na comunidade e na vida social mais ampla, mencionando também que o protagonismo seria

um método pedagógico que se baseia num conjunto de práticas e vivências, que tem como foco a criação de espaços e condições que propiciem ao adolescente empreender ele próprio a construção de seu ser em termos pessoais e sociais. (COSTA, 2001, p. 5 apud KLEIN, 2004, p. 12, grifo nosso).

Ainda segundo Klein (2004), o pedagogo assume como um dos mais fortes argumentos em defesa do protagonismo juvenil a ideia de que o jovem somente poderá atuar como cidadão na medida em que tomar conhecimento de sua realidade social e comunitária. Entretanto, "cabe indagar sobre qual é o entendimento do que seja, de fato, o conhecimento da realidade, quais as condições desse conhecimento, bem como o que implica a atuação cidadã" (KLEIN, 2004, p. 96).

\section{A acolhida do conceito de protagonismo juvenil pela escola}

No que diz respeito a canais institucionais de participação dos discentes na gestão da escola, Ferreti et al. (2004) listam os grêmios estudantis, datados da década de $1960^{10}$, e os conselhos escolares, datados, em alguns estados da federação, dos anos $1980^{11}$. Os autores mostram que nos anos 1990 foram emitidos diferentes documentos oficiais - tanto em nível federal, quanto nos estados - que explicitaram e valorizaram tal participação, tornando cada unidade escolar

um espaço pedagógico atraente e desafiador para os jovens, de modo a favorecer seu progresso intelectual, social e afetivo, e, ainda, um espaço democrático, confiável e culturalmente rico para pais e para a comunidade, com vistas a um intercâmbio fecundo entre a escola e o seu entorno. (FERRETI et al., 2004, p. 412).

da sociedade do conhecimento a necessidade de uma aprendizagem ao longo de toda vida, fundamentada nestes pilares que são, concomitantemente, do conhecimento e da formação continuada. Disponível em: http://www.gestaoescolar.diaadia.pr.gov.br/modules/conteudo/ conteudo.php?conteudo=337. Acesso em: 22 ago. 2019. Esta pequena explicação foi retirada do site da Secretaria de Educação do Paraná e demonstra a penetração que os conceitos deste relatório tiveram no Brasil, embasando uma série de políticas públicas para a educação. 9 Segundo Souza, o conceito de autonomia foi ressignificado pelo neoliberalismo, propondo a atuação do indivíduo apartada das ideologias que "Ihe cerceariam a 'liberdade' de pensamento e de ação. No entanto, as atuais noções, tanto de autonomia quanto de liberdade, assemelham-se mais ao estado de isolamento" (SOUZA, 2006, p. 93).

10 “O grêmio estudantil é uma forma de organização colegiada ou hierárquica composta pelos alunos de uma escola com o objetivo de representar o seu corpo discente de forma livre e autônoma. Ele promove o diálogo entre estudantes e os profissionais que atuam na unidade, como professores, coordenadores e diretor. Além da defesa dos interesses do alunado, o grêmio também é responsável por realizar atividades culturais e esportivas no ambiente escolar" (TODOS PELA EDUCAÇÃO, 2018a). Assim como o Conselho de Escola e a Associação de Pais e Mestres (APM) é um instrumento de gestão democrática nas escolas.

11 “O Conselho é responsável por zelar pela manutenção e por participar da gestão administrativa, pedagógica e financeira da escola. Além disso, tem um papel fundamental na democratização da Educação. São órgãos colegiados que debatem, acompanham e deliberam sobre questões político-pedagógicas, administrativas e financeiras das escolas. São formados por representantes de pais, alunos, professores, demais funcionários da escola, membros da comunidade local, eleitos pela própria comunidade escolar, e o diretor da unidade escolar. Por ser um espaço que reúne diferentes atores da comunidade escolar, o Conselho tem um papel muito importante na democratização da Educação e da escola. As ações do conselho colaboram, por exemplo, para conferir mais transparência e legitimidade às decisões tomadas. Além disso, o conselho proporciona mais controle da sociedade sobre a execução da política educacional" (TODOS PELA EDUCAÇÃO, 2018b). 
Na educação, as Diretrizes Curriculares Nacionais para o Ensino Médio (DCNEM) (1998b) - constituem o meio legal mais importante para a difusão do protagonismo juvenil. Segundo Souza (2006), concorreu para isso um movimento internacional de reafirmação do papel da educação como fator de desenvolvimento nos anos 1990. Ao possibilitar maiores oportunidades aos indivíduos, a educação seria instrumento para "o aumento do nível de renda, redução do desemprego e superação da pobreza, constituindo, portanto, fator de mobilidade e equidade sociais", e como mecanismo de inclusão social "seria fundamental para a consolidação da democracia" (SOUZA, 2006, p. 169). Os jovens, objetos privilegiados da educação e detentores de rico "potencial humano", passaram a constituir "importante segmento a que devem dirigir-se os investimentos em educação, e o ensino médio passou a ser encarado como o momento mais propício para o desenvolvimento das capacidades requeridas para a integração social” (RIVERO, 2000, p. 128-133 apud SOUZA, 2006, p. 169-170).

Em sua análise, Souza (2006) mostra que a referência para os escritos de Costa e os trabalhos desenvolvidos por instituições da sociedade civil com o protagonismo juvenil foi o Relatório para a Unesco da Comissão Internacional sobre Educação para o Século XXI, o já citado "Relatório Delors", principal responsável pela introdução dos conceitos de competências e habilidades, presentes, por exemplo, no Currículo da Cidade de São Paulo (SME, 2019a) e na Base Nacional Comum Curricular (BNCC) ${ }^{12}$ (MEC, 2018). Com ênfase no polo da aprendizagem, passa a ser responsabilidade do indivíduo (estudante) desenvolver as competências e aprender as habilidades relacionadas, necessárias para acompanhar as demandas da nova ordem. Aprender a ser, aprender a fazer, aprender a conviver e aprender a conhecer são as habilidades passíveis de aprendizagem e treino na escola, uma vez que todas são de ordem prática. Aprender a "participar" também é uma habilidade a ser aprendida, já que concebida como "atividade" (fazer).

Por intermédio de Costa e da forte atuação de organizações como o Instituto Ayrton Senna a prática do protagonismo saiu das organizações da sociedade civil e adentrou as escolas. O projeto será a forma privilegiada para o trabalho pedagógico com o protagonismo: "uma forma diferente e fecunda de abordar os conteúdos curriculares", que, "por tratar-se de uma metodologia integradora de disciplinas e áreas culturais distintas, torna-se uma grande promotora e facilitadora das atividades interdisciplinares" (COSTA, 2001, p. 104 apud FERRETTI et al., 2004, p. 420).

Os pesquisadores da Fundação Carlos Chagas mostram que de acordo com as DCNEM, cabe à escola contribuir para:

[...] a aprendizagem de competências de caráter geral, visando a constituição de pessoas mais aptas a assimilar mudanças, mais autônomas em suas escolhas, mais solidárias, que acolham e respeitem as diferenças, pratiquem a solidariedade e superem a segmentação social. (BRASIL, 1998, p. 17 apud FERRETTI et al., 2004, p. 420-421, grifo do autor).

As Diretrizes (1998b) veem o protagonismo como uma forma de inserção da juventude, principalmente a juventude pobre, na ordem social vigente, confirmando o que Souza (2006) defende em sua tese. Ao defender a necessidade de desenvolvimento de um ser humano aberto à diversidade cultural de seu tempo e às responsabilidades sociais, e de métodos ativos da contextualização dos conteúdos disciplinares e de um certo nível de integração de tais conteúdos, de modo que façam sentido para os jovens (FERRETTI et al., 2004, p. 422), o discurso do protagonismo juvenil encontra acolhida entre os educadores. É importante lembrar que são as escolas públicas que recebem a maior parcela de jovens no país e, uma vez que os documentos oficiais adotam o discurso do protagonismo, as escolas tornam-se mais receptivas a ele sem criticá-lo.

12 O Currículo da Cidade de São Paulo do Ensino Fundamental é um documento da Secretaria Municipal de Educação lançado em 2017. O movimento de atualização do currículo envolveu mais de 43 mil estudantes e 16 mil professores, em paralelo às discussões sobre a Base Nacional Comum Curricular (BNCC) que se faziam nacionalmente. A Base Nacional Comum Curricular é um documento normativo que define o conjunto de aprendizagens essenciais que todos os alunos devem desenvolver ao longo das etapas e modalidades da Educação Básica. Iniciado de forma colaborativa em 2015 foi homologado definitivamente em 14/12/2018, com a conclusão da redação da etapa do Ensino Médio. Disponível em: http://basenacionalcomum.mec.gov.br/a-base. Acesso em: 27 maio 2019. 


\section{O protagonismo juvenil na BNCC e no Currículo da Cidade de São Paulo}

Na BNCC (MEC, 2018) o protagonismo não está bem definido: pode ser sinônimo de "autoria", "autonomia", "participação", conceitos igualmente não definidos no documento. Logo, podemos afirmar que o termo apresenta o "hibridismo semântico", polissemia ou imprecisão apontados por Souza (2006) e Ferretti et al. (2004) em suas pesquisas.

O foco da BNCC (MEC, 2018) está no desenvolvimento de competências, servindo à formação de um sujeito preparado para viver em um "novo cenário mundial" e que saiba comunicar-se, ser criativo, analítico-crítico, participativo, aberto ao novo, colaborativo (sinônimo para obediente?), resiliente (receptivo às incertezas provocadas pelo avanço do neoliberalismo?), produtivo (para o capital?) e responsável (segue as regras?) (MEC, 2018, p. 14), habilitado para

aprender a aprender, saber lidar com a informação cada vez mais disponível, atuar com discernimento e responsabilidade nos contextos das culturas digitais, aplicar conhecimentos para resolver problemas, ter autonomia para tomar decisões, ser proativo para identificar os dados de uma situação e buscar soluções, conviver e aprender com as diferenças e as diversidades. (MEC, 2018, p. 14).

Observa-se, assim, a influência do "Relatório Delors" (SOUZA, 2006) na sua elaboração e a necessidade de formar sujeitos integrados à ordem neoliberal, entendida, talvez, como insuperável ou impossível de ser contestada.

Percebemos, na BNCC (MEC, 2018), a necessidade de "desenvolver" o protagonismo nos estudantes desde seu ingresso no Ensino Fundamental até sua saída da escola, já no Ensino Médio. Na parte dedicada a esta última etapa da Educação Básica o protagonismo aparece muito associado ao mundo do trabalho e também à participação social, incentivando a busca de soluções para os problemas existentes.

Concluindo o raciocínio, o documento não conceitua o que entende por "protagonismo juvenil" ou até mesmo "protagonismo". Parece que, sendo um termo "popular" nos documentos oficiais sobre educação, seu uso se tornou indiscriminado, os sentidos se multiplicaram e não foram problematizados.

No Currículo da Cidade de São Paulo (SME, 2019a), que organiza os currículos escolares das escolas municipais de São Paulo, parte da concepção de que a criança e o adolescente são sujeitos de direito e devem opinar e participar das escolhas capazes de influir nas suas trajetórias individuais e coletivas. Logo, compreende-se que o Currículo,

bem como os espaços, tempos e materiais pedagógicos disponibilizados pelas unidades educativas, precisa acolhê-los na sua integralidade e promover a sua participação. Para tanto, faz-se necessário conhecer as suas aspirações, interesses e necessidades, bem como atentar para as mudanças que ocorrem ao longo do seu desenvolvimento. (SME, 2019a, p. 18).

Neste documento o termo "protagonismo" aparece cinco vezes no componente Língua Portuguesa, sendo que em uma dessas ocorrências vem acompanhado de "juvenil”. Mais uma vez há uma aproximação entre "autoria" e "protagonismo" e o termo não está totalmente definido. O protagonismo também se associa ao professor, denominado "ator educativo", reforçando sua ligação com o conceito de "ator social" apontado por Souza (2006) em sua tese e sobre o qual falamos neste artigo.

Professores são protagonistas do currículo: O professor é o sujeito principal para a elaboração e implementação de um currículo, uma vez que tem a função de contextualizar e dar sentido aos aprendizados, tanto por meio dos seus conhecimentos e práticas, quanto pela relação que estabelece com seus estudantes. Para tanto, os educadores precisam reconhecer o seu papel de protagonistas nesse processo, sentindo-se motivados e tendo condições de exercê-lo. (SME, 2019a, p. 20, grifo nosso). 
Em sua parte comum, o Currículo da Cidade (SME, 2019a, p. 44) afirma que o Ciclo Autoral (7o a 9o ano do Ensino Fundamental) destina-se aos adolescentes e tem por objetivo ampliar os saberes dos estudantes de forma a permitir que compreendam melhor a realidade na qual estão inseridos, explicitem as suas contradições e indiquem possibilidades de superação. Uma das estratégias sugeridas para a consecução deste objetivo é o Trabalho Colaborativo de Autoria (TCA $)^{13}$, que permite aos estudantes "reconhecer diferenças e participar efetivamente na construção de decisões e propostas visando à transformação social è à construção de um mundo melhor" (SME, 2019a, p. 45, grifo nosso).

O documento nomeia essa estratégia de "protagonismo juvenil", enfatizando o desejo de os estudantes envolverem-se em projetos voltados à solução de problemas reais. Entendo, assim, que o Currículo (SME, 2019a) mostra-se alinhado à concepção neoliberal de "protagonismo juvenil" ao incentivar que os próprios estudantes identifiquem e sugiram soluções para problemas públicos, num contexto em que o Estado se desresponsabiliza pelas situações provocadas pela sua atuação ou ausência dela.

\section{Como ressignificar o conceito de protagonismo, então?}

No artigo Escola e participação juvenil:é possível esse diálogo?, Dayrell et al. (2010, p. 238-239) se perguntam em que medida o modelo de organização escolar e suas dinâmicas produzem um ambiente propício para o desenvolvimento de experiências de participação juvenil. Por ser uma das poucas instituições públicas que atingem de forma mais universal a juventude brasileira, a escola seria o local privilegiado para incentivo à participação. Participação esta que extrapolaria seus muros e levaria a uma inserção ativa na vida social e política do país.

Dados de pesquisa realizada pelos autores com jovens na região metropolitana de Belo Horizonte mostraram um esvaziamento das instâncias políticas clássicas, como os partidos e sindicatos e até mesmo o movimento estudantil como espaços privilegiados da participação juvenil, consequência, talvez, do avanço da ordem neoliberal, como apontou Souza (2006) em sua tese, ou destas instâncias serem entendidas como espaços de participação adulta, sendo pouco acolhedoras das demandas juvenis.

Neste contexto, Dayrell et al. (2010, p. 245) perguntam:

Em que medida a instituição escolar fomenta experiências que estimulam o aprendizado e a experimentação em torno da participação social e política? A organização escolar em sua forma e conteúdo tem priorizado uma formação que permite aos jovens se posicionarem criticamente diante da realidade e vislumbrarem formas de ação coletiva em torno de suas demandas? Ela se preocupa em estimular a participação na gestão escolar e a organização autônoma dos estudantes? Tendo como foco a participação social e política, qual lugar a escola ocupa na vida dos jovens?

Em sua dissertação sobre os sentidos da participação e das experiências escolares de adolescentes dos últimos anos do Ensino Fundamental ${ }^{14}$, Matheus Boucault de Pasquali entende que a participação se coloca como um importante critério

\footnotetext{
13 De acordo com a Instrução Normativa SME no 46, de 12 de dezembro de 2019, o TCA tem como objetivo a mobilização dos conhecimentos e habilidades presentes na Matriz de Saberes, integrante do Currículo da Cidade, e a busca de soluções ancoradas na realidade e nos desafios do território e do mundo contemporâneo. Foi concebido como sistematização dos projetos e pesquisas realizados ao longo do Ciclo Autoral (7o a 9o anos) e sua elaboração implica um processo que envolve a leitura, a escrita, análise crítica e produção (SME, 2019b). 14 Seu alvo são estudantes integrantes da CPA (Comissão Própria de Avaliação), um mecanismo institucional de avaliação participativa das escolas municipais de Campinas implantadas no ano de 2008. Para Pasquali as comissões se mostraram interessantes para um trabalho empírico acerca da participação dos estudantes dos últimos anos do Ensino Fundamental (PASQUALI, 2014, p. 45).
} 
na caracterização do sujeito em seu processo de transição da condição de heteronomia da infância para uma posição de maior autonomia da vida adulta, no momento em que passa a assumir novas responsabilidades nos grupos e instituições dos quais faz parte, compondo práticas e influenciando na organização do espaço social. (PASQUALI, 2014, p. 11).

O pesquisador parte do conceito de adolescência como primeiro momento da juventude no qual a participação se constituiria como um elemento significativo em seus processos de construção identitária em busca de cada vez mais autonomia e afirmação de suas identidades juvenis (PASQUALI, 2014, p. 14-15). Além disso, entende que a escola é uma instituição que permanece como espaço de socialização para os adolescentes e jovens. Ainda que não seja o único, "é referência importante na construção da experiência juvenil, onde se vive parte significativa das intensas transformações relacionadas a este momento da vida" (PASQUALI, 2014, p. 17).

O trabalho de Pasquali (2014) me proporcionou pensar em outro sentido para o protagonismo juvenil, qual seja a participação dentro do espaço escolar. Logo, o conceito não adquire os sentidos construídos pela ordem neoliberal que apresentei e critiquei ao longo deste artigo.

Para o estudo de caso de minha pesquisa escolhi uma escola municipal situada na zona leste do município de São Paulo ${ }^{15}$. A EMEF Professor Antônio Duarte de Almeida atende crianças e adolescentes do 1o ao 9o ano da educação básica e tem como um dos principais eixos de seu Projeto Político Pedagógico (PPP) (EMEF..., 2019) o incentivo ao protagonismo juvenil. Mesmo não sendo devidamente conceituado ou problematizado, observei que o sentido que adquire na prática da escola é de acolhimento da participação dos estudantes, independente de sua idade. Aliás, não apenas os estudantes, mas familiares, funcionários, professores e membros da gestão participam ativamente das decisões que envolvem a rotina da escola frequentando as reuniões de Conselho de Escola.

A falta de emprego, violência, analfabetismo, baixa renda, tráfico de drogas, tornam o Parque Guarani, distrito no qual a escola está localizada, uma região de alta vulnerabilidade social. Neste contexto, a escola conseguiu ressignificar suas práticas pedagógicas tornando-se um oásis para seus mais de 900 estudantes. Atua de maneira a ir ao encontro das necessidades da comunidade, desde as questões de aprendizagem até as de comportamento social, e oferece uma série de projetos extracurriculares, importantes para a fruição da condição juvenil.

Situação bem diferente da apresentada por Dayrell et al. (2010) em seu artigo. Apenas 33,6\% dos jovens entrevistados durante a pesquisa que realizaram afirmaram existir atividades culturais na escola que frequentavam em 2004, evidenciando um distanciamento da escola em relação à realidade juvenil. Se a vivência de tais expressões faz parte das práticas juvenis, perguntam-se: a escola que atende a esse público não deveria incluí-las na sua organização, nos seus tempos e espaços escolares? (DAYRELL et al., 2010, p. 246 ${ }^{16}$. A mesma pesquisa ainda revelou preocupação por uma melhor qualificação dos professores, principalmente no que dizia respeito ao desenvolvimento de uma relação humana e pedagógica mais próxima com os alunos (DAYRELL et al., 2010, p. 249). Essa proximidade é uma realidade na EMEF Professor Antônio Duarte de Almeida, permitindo a adesão dos estudantes não só à participação nas instâncias decisórias, mas também às atividades pedagógicas.

Nesta escola a mudança teve início em 2010, com a chegada das séries iniciais do ensino de 9 anos. A equipe começou a trabalhar com projetos, os quais envolvem pesquisa, conhecimento, organização de sequências didáticas e produto final ${ }^{17}$. Tal forma de organizar e realizar o trabalho

\footnotetext{
15 O projeto de pesquisa passou por apreciação do Comitê de Ética em Pesquisa (CEP) da Unicamp e foi aprovado sob o registro CAAE: 97483918.5 .0000 .8142$.

16 Dayrell et al. (2010, p. 247) inferem, prosseguindo o raciocínio, a respeito da diminuição das atividades culturais quanto mais elevado o grau de ensino: “Quanto mais inserido no mundo do 'pensar' como tradicionalmente se atribui ao Ensino Superior e do 'fazer' como é costume atribuir à vida adulta, mais a escola diminui a sua presença enquanto espaço cultural, de lazer e de possibilidade de ações coletivas, transformando-se em uma instituição cada vez mais livresca e com ênfase nos conteúdos."

17 Os projetos mencionados no PPP da escola são: Retratos e Identidades: Brasil/África, Retratos e Identidades: descobrindo os anos 1960, o aniversário de 40 anos da escola, Retratos e Identidades: Meio Ambiente e Sustentabilidade, Identidade Brasileira: Brasil Nossa Casa, Cultura Popular (EMEF..., 2019, p. 23-24).
} 
pedagógico foi, de acordo com o PPP, "um divisor de águas para a efetivação da Pedagogia por Projetos" (EMEF..., 2019, p. 24) hoje praticado pela escola.

Em 2017, a EMEF Professor Antônio Duarte de Almeida reformulou a organização dos tempos e espaços destinados à aprendizagem, alicerçado de um lado pela crítica ao modelo tradicional de ensino-aprendizagem, e por outro pela ampla participação de toda comunidade escolar, garantida pela ampliação dos canais legais de participação, como Conselho de Escola, mencionado anteriormente, o Grêmio Estudantil, reuniões e assembleias de classe.

Intitulado Projeto Duarte ${ }^{18}$, esta reformulação comunga, ainda segundo o PPP, com uma escola aberta, democrática, participativa, autônoma, investigativa e autoral, "em que alunas e alunos constituem-se como sujeitos históricos em cada momento de sua vida, e que professoras e professores sejam sujeitos do processo educativo escolar" (EMEF..., 2019, p. 81-82). Como Dayrell (2007, p. 1105) expõe, em outro artigo, "quando o ser humano passa a se colocar novas interrogações, a pedagogia e a escola também têm de se interrogar de forma diferente".

Ao compartilhar as decisões, incluindo as que envolvem as temáticas de estudos em sala de aula, a participação se faz necessária. Ideias e sugestões encontram espaço para serem apresentadas e entrarem em disputa com outras, sem hierarquia. Os estudantes reconhecem e valorizam estes espaços de escuta, debates e participação, mesmo não estando familiarizados com o significado de protagonismo juvenil. Entrevistas com estudantes de uma turma de 9o ano ${ }^{19}$, colhidas durante o trabalho de campo, comprovam esta afirmação:

Aqui na região ainda acho o Duarte a melhor escola pelo fato de que eles gostam de trabalhar muito a democracia, gostam muito de escutar os alunos, é onde poucas escolas têm isso, né? Os alunos não têm muita voz. E aqui o que eu admiro muito no Duarte e sempre vou admirar é isso: que os alunos sempre têm a voz.

Eu sempre falo que o Duarte é muito mãe, é muito família, porque aqui todo mundo se ajuda, tanto os professores ajudam os alunos [...] não tem essa hierarquia de professor ser professor e aluno ser aluno e é isso, você faz o que eu falo e obedece e pronto. Eu falo que o Duarte é muito família porque ele realmente é. Ele sempre acolhe novas ideias tanto dos alunos, tanto de moradores, da comunidade que mora por perto.

Eu gosto. Eu gosto que a escola dá uma liberdade para os alunos, eu gosto desse fato. Assim, a gente tem a liberdade de falar até com os professores tanto quanto [com] os diretores. Os alunos têm voz aqui, eu gosto disso.

Falas como essas sugerem porque o protagonismo juvenil se constitui em um dos pilares da prática da escola. Ao acolher e incentivar a participação dos estudantes, a atuação dos profissionais da EMEF Professor Antônio Duarte de Almeida nos mostra que é possível construir outro sentido para o protagonismo juvenil - e também para a escola pública -, promovendo não a cooptação mas a emancipação dos sujeitos jovens que ali estão. Ao contrário do que Dayrell (2007, p. 1117) aponta, ao se abrir para receber um novo público, a EMEF Antônio Duarte escolheu se redefinir internamente, criando pontos de diálogo com os sujeitos e sua realidade.

18 Desde 2017, o Projeto Duarte (EMEF..., 2019) percorreu os caminhos legais para ser reconhecido pela Diretoria Regional de Ensino de Itaquera e Secretaria Municipal de Educação. Finalmente, foi reconhecido pelo Conselho Municipal de Educação como Projeto Especial/Experimental no final de 2019 (Parecer CME no 18/19, aprovado em sessão plenária no dia 12 de dezembro, e publicado no Diário Oficial da Cidade em 19/12/2019) (SÃO PAULO, 2019).

19 As entrevistas aconteceram entre o final de outubro e início de novembro de 2019. 


\section{Referências}

DAYRELL, Juarez. A escola "faz" as juventudes? Reflexões em torno da socialização juvenil. Educação \& Sociedade, Campinas, v. 28, n. 100, p. 1105-1128, out. 2007.

DAYRELL, Juarez; GOMES, Nilma Lino; LEÃO, Geraldo. Escola e participação juvenil: é possível esse diálogo? Educar em Revista, Curitiba, v. 26, n. 38, p. 237-252, set./dez. 2010.

CONSELHO NACIONAL DE EDUCAÇÃO (CNE). Câmara de Educação Básica. Resolução no 3, de 26 de junho de 1998. Institui as Diretrizes Curriculares Nacionais para o Ensino Médio. Brasília, DF: Câmara de Educação Básica, 1998a.

CONSELHO NACIONAL DE EDUCAÇÃO (CNE). Câmara de Educação Básica. Parecer n 15/98. Diretrizes Curriculares Nacionais para o Ensino Médio. Brasília, DF: Câmara de Educação Básica, 1998b.

EMEF PROFESSOR ANTÔNIO DUARTE DE ALMEIDA. Projeto Político Pedagógico. São Paulo: EMEF Professor Antônio Duarte de Almeida, 2019. Disponível em: https://drive.google.com/file/d/1R9cQDMMfkXydlj_xAhuqxiGJNnCn5JRs/view. Acesso em: 26 jan. 2021.

FERRETTI, Celso João; TARTUCE, Gisela Lobo Baptista Pereira; ZIBAS, Dagmar Maria Leopoldi. Protagonismo Juvenil na literatura especializada e na reforma do Ensino Médio. Cadernos de Pesquisa, São Paulo, v. 34, n. 122, p. 411-423, maio/ago. 2004.

KLEIN, Bianca Larissa. Protagonismo Juvenil e Cidadania: uma proposta pedagógica burguesa. 2004. 128 f. Dissertação (Mestrado) - Faculdade de Educação, Universidade Federal do Paraná, Curitiba, 2004.

MINISTÉRIO DA EDUCAÇÃO (MEC). Base Nacional Comum Curricular. Brasília, DF: MEC, 2018.

NONATO, Symaira Poliana et al. Por uma pedagogia das juventudes. In: DAYRELL, Juarez (org.). Por uma pedagogia das juventudes: experiências educativas do Observatório da Juventude da UFMG. Belo Horizonte: Mazza Edições, 2016. p. 249-304.

PASQUALI, Matheus Boucault de. Juventude e participação: os sentidos da experiência juvenil em duas escolas municipais de Campinas - SP. 2014. 161 f. Dissertação (Mestrado) - Programa de Pós-Graduação em Educação, Universidade Federal de São Carlos, Campus Sorocaba, Sorocaba, 2014.

SÃO PAULO (Cidade). Conselho Municipal de Educação. Parecer CME no 18/19, Aprovado em Sessão Plenária de 12 de dezembro de 2019. [Projeto Pedagógico Especial]. Diário Oficial da Cidade de São Paulo: Gabinete do Secretário, São Paulo, ano 64, n. 239, p. 15-16, 19 dez. 2019.

SECRETARIA MUNICIPAL DE EDUCAÇÃO (SME) (São Paulo). Currículo da Cidade: Ensino Fundamental: componente curricular: Língua Portuguesa. 2. ed. São Paulo: SME/COPED, 2019a.

SECRETARIA MUNICIPAL DE EDUCAÇÃO (SME) (São Paulo). Instrução Normativa SME no 46, de 12 de dezembro de 2019. Dispõe sobre a reorganização do Trabalho Colaborativo de Autoria - TCA [...]. São Paulo: Secretaria Municipal de Educação, 2019b.

SIQUEIRA, Thais Batista. (Re)Descobrindo o prazer de ler: o incentivo à prática de leitura entre estudantes do Ensino Fundamental 2. 2020. Dissertação (Mestrado) - Faculdade de Educação, Universidade Estadual de Campinas, Campinas, 2020.

SOUZA, Regina Magalhães de. O discurso do protagonismo juvenil. 2006. $351 \mathrm{f}$. Tese (Doutorado) - Programa de Pós-graduação em Sociologia, Universidade de São Paulo, São Paulo, 2006.

TODOS PELA EDUCAÇÃO. Perguntas e respostas: o que é um grêmio escolar? Todos pela Educação, São Paulo, 18 mar. 2018a. Disponível em: https://todospelaeducacao.org.br/noticias/perguntas-e-respostas-o-que-e-um-gremio-escolar/. Acesso em: 30 jan. 2021.

TODOS PELA EDUCAÇÃO. Perguntas e respostas: como funcionam os conselhos escolares? Todos pela Educação, São Paulo, 22 jan. 2018b. Disponível em: https://www.todospelaeducacao.org.br/conteudo/perguntas-e-respostas-como-funcionam-os-conselhos-escolares. Acesso em: 17 ago. 2019.

Data de submissão: 31/01/2021

Data de aceite: 12/02/2021 